\title{
Modos de aprender em tempos de pandemia: Deficiências e importância da inclusão digital para alunos da rede pública
}

\author{
Ways of learning in times of pandemic: Deficiencies and the importance of digital inclusion for \\ public school students
}

Formas de aprender en tiempos de pandemia: Deficiencias y la importancia de la inclusión digital para los estudiantes de escuelas públicas

Recebido: 28/05/2021 | Revisado: 06/06/2021 | Aceito: 17/06/2021 | Publicado: 02/07/2021

\author{
Herbert Fernando Martins de Oliveira \\ ORCID: https://orcid.org/0000-0003-2366-7070 \\ Universidade Federal de Viçosa, Brasil \\ E-mail: herbert.martins@ufv.br \\ Rodrigo Florencio da Silva \\ ORCID: https://orcid.org/0000-0002-9644-7645 \\ Instituto Politécnico Nacional, México \\ E-mail: rflorencio@ipn.mx \\ Vilmar Alves Pereira \\ ORCID: https://orcid.org/0000-0003-2548-5086 \\ Universidad Internacional Iberoamericana, México \\ E-mail: vilmar1972@gmail.com
}

\begin{abstract}
Resumo
Esse artigo trata da questão central contemporânea: o acesso digital à educação. Trata-se de um estudo de revisão bibliográfica que está organizado da seguinte forma: inicialmente, o texto traz um parâmetro entre o que foi e o que se tornou a educação na atualidade devido ao fechamento das instituições educacionais dentro do contexto de pandemia, mostrando as diferenças primárias quanto à forma de ensinar e aprender. Mostra também quão excludente e desmotivadora é a falta de acesso às novas tecnologias para alunos da educação básica pública, fora da sala de aula, em um ambiente que exaspera distrações. Observa-se ainda como o corpo docente tem trabalhado para o enfrentamento das dificuldades, bem como possíveis soluções para os problemas de conectividade oriundos da má distribuição de renda. Foram utilizados para fins desse estudo artigos científicos de autores renomados, publicados em revistas reconhecidas no Brasil e no mundo, além de utilizarmos da experiência própria dentro do contexto de pandemia, no trabalho, em casa e nos estudos para endossar o projeto. Uma das conclusões da pesquisa indica o quão distante está a realidade do desejo de haver acessibilidade a todos para uma qualificação igualitária, que possa garantir uma disputar legal no mundo de trabalho. Mostra também que devido à falta de conhecimento, inúmeros trabalhadores semiletrados não conseguem acessar seus direitos, tampouco ajudar os filhos nos afazeres escolares online.
\end{abstract}

Palavras-chave: Educação; EaD; Pandemia; Covid-19; Aprendizagem.

\begin{abstract}
This article addresses the central contemporary issue: digital access to education. This is a bibliographic review study that is organized as follows: initially, the text brings a parameter between what education has been and what has become today due to the closure of educational institutions within the context of a pandemic, showing the primary differences in the way of teaching and learning. It also shows how exclusionary and demotivating the lack of access to new technologies is for students in public basic education, outside the classroom, in an environment that exasperates distractions. It is also observed how the faculty has worked to face the difficulties, as well as possible solutions to the connectivity problems arising from the poor distribution of income. For the purposes of this study, scientific articles by renowned authors, published in recognized journals in Brazil and in the world, were used, in addition to using our own experience within the context of the pandemic, at work, at home and in studies to endorse the project. One of the conclusions of the research indicates how distant the reality is from the desire to have accessibility for all for an equal qualification, which can guarantee a legal dispute in the world of work. It also shows that due to the lack of knowledge, countless semi-literate workers are unable to access their rights, nor help their children with schoolwork online.
\end{abstract}

Keywords: Education; EaD; Pandemic; Covid-19; Learning. 


\section{Resumen}

Este artículo aborda el tema central contemporáneo: elacceso digital a laeducación. Se trata de unestudio de revisión bibliográfica que se organiza de lasiguientemanera: inicialmente, el texto aporta unparámetro entre lo que ha sido laeducación y lo que se ha convertido hoydebido al cierre de instituciones educativas enel contexto de una pandemia, mostrando lasprincipales diferencias enla forma de laenseñanza y elaprendizaje. Tambiénmuestracuánexcluyente y desmotivador es la falta de acceso a lasnuevastecnologías para losestudiantes de educación básica pública, fueradel aula, enun entorno que exaspera lasdistracciones. También se observa cómolafacultad ha trabajado para enfrentar lasdificultades, así como posibles soluciones a los problemas de conectividad derivados de la mala distribucióndelingreso. Para los propósitos de este estudio, se utilizaron artículos científicos de autores reconocidos, publicados en revistas reconocidasen Brasil y enel mundo, además de utilizar nuestrapropiaexperienciaenel contexto de la pandemia, eneltrabajo, enelhogar y enestudios para avalarelproyecto. Una de lasconclusiones de lainvestigación indica cuán distante está larealidaddeldeseo de teneraccesibilidad para todos por una calificación igual, lo que puedegarantizar una disputa jurídica enel mundo deltrabajo. Tambiénmuestra que debido a la falta de conocimiento, innumerablestrabajadores semianalfabetos no puedenacceder a sus derechosniayudar a sus hijosconlastareas escolares en línea.
\end{abstract}

Palabras clave: Educación; Educación a distancia; Pandemia; Covid-19; Aprendizaje.

\title{
1. Introdução
}

Em tempos de grandes mudanças o processo de aprendizagem não é somente uma necessidade, mas um fato consumado, do contrário, quem não se adapta, não consegue acompanhar o desenrolar da história e fica pelo caminho. O ser humano está acostumado a ser comandado e para tanto, os que se destacam na multidão, graças a sua aprendizagem à cerca das novas formas de se viver, trabalhar, conquistar espaço, passam assim, a liderar. Isso também se reflete nos novos formatos adquiridos pela educação e segundo Munastiwi e Puryono (2021), a pandemia de Coronavírus (COVID-19) mudou a forma de interação das pessoas. No contexto atual, de pandemia universal pela Covid-19, quem não se adequar ao EaD - Ensino a Distância, vai ficar para trás no trem da história, mas de acordo com Putra et al. (2020), vários obstáculos são relatados em relação à implementação de atividades de "aprender em casa". Justo seria que todos evoluíssem da mesma forma, porém o processo de seleção para que se destaque aquele que pode liderar na mudança, não aconteceria. Isso, no entanto, não significa que as pessoas de um modo geral não mereçam ter as mesmas chances. Todos deveriam ter direito as mesmas condições para que ocorra o processo de transformação. É nesse ínterim, que esse estudo vem tratar da universalização das políticas públicas para garantia de acesso a uma condição igualitária para que todos possam trilhar o caminho da mudança sem prejuízos para quaisquer indivíduos, independente da sua condição financeira. Segundo Thomas H. Marshall (1967), referência de Carlos Roberto Jamil Cury (2012):

A história do direito à educação escolar é semelhante à luta por uma legislação protetora dos trabalhadores da indústria nascente, pois, em ambos os casos, foi no século XIX que se lançaram as bases para os direitos sociais como integrantes da cidadania. [...] "a educação é um pré-requisito necessário da liberdade civil" e, como tal, um prérequisito do exercício de outros direitos. O Estado, neste caso, ao interferir no contrato social, não estava conflitando com os direitos civis. Afinal, esses devem ser utilizados por pessoas inteligentes e de bom senso e, para tanto, segundo o autor, o ler e o escrever são indispensáveis (Cury 2012).

É sabido que quem detém o maior poder aquisitivo, tem acesso às melhores tecnologias, em detrimento, da população menos favorecida que mal consegue acessar os direitos mais básicos, como moradia, alimentação e escola de qualidade e com base em Arruda (2020), a falta de acesso à tecnologia e à internet atinge uma parcela considerável da população. Educação a Distância é um assunto relativamente novo, ainda com muitas lacunas, e em andamento, uma novidade para alunos, e ainda mais para professores. Partindo do princípio da igualdade preconizado pela Constituição Federal de 1988, e antes dela a Declaração Universal dos Direitos Humanos, que salienta que somos todos iguais perante a Lei, entende-se, que todos tenham o mesmo direito e consequentemente, mesmas obrigações. Contudo, a realidade mostra uma desigualdade latente e crescente 
que aos olhos da justiça é ilegal, aos olhos humanos é desleal, e irremediavelmente, real. Não é possível falar de igualdade, liberdade, fraternidade, educação, justiça, sem observar as mazelas que distanciam o povo brasileiro de direitos básicos, como educação, saúde, segurança, lazer, previdência social, proteção à infância e assistência a todos os desamparados. Esta é a finalidade dessas duas leis, a melhoria das condições de vida dos menos favorecidos, concretizando assim, a igualdade social, porém, muito pouco tem sido feito para a efetivação desses direitos, quer pela vontade política dos governantes, quer pelo poder imensurável do capital, quer pelo culto à corrupção em todos os níveis da sociedade brasileira.

Políticas públicas são pensadas, repensadas, colocadas em prática, mas a sua efetividade é questionável, assim o governo finge que garante direitos, o capital finge que se importa e o povo continua a mercê da própria sorte. Não obstante, o governo reitera ano após ano a necessidade de se manter o povo refém dessas necessidades básicas, utilizando-se dessas condições para conseguir se manter no poder. Quanto mais dependente mais fácil de ser manipulado, e apesar de o povo estar completamente nas mãos dos comandantes do sistema, ainda assim mantém acessa uma chama de esperança de uma vida melhor. Uma vida melhor impreterivelmente, passa por uma boa educação, e quando se fala de educação, não se trata apenas da que se recebe em casa, mas da que se recebe na escola que deveria ser de qualidade. Claro que apesar de envidar esforços os professores sofrem com a falta de infraestrutura, com a falta de segurança, além de baixos salários e muitas vezes salários atrasados. Quisera que as escolas públicas oferecessem a rigor uma educação de qualidade, com acessibilidade, equipamentos mais modernos e tecnologias de ponta para que todos os alunos pudessem ter igual condição tais quais escolas privadas. Assim, o trabalho de docentes se torna um pouco mais desafiador. A escola não é atrativa, o formato secular da educação, no que tange a evolução no campo educacional, parece ter se livrado unicamente da palmatória, porque apesar da enorme evolução tecnológica o meio acadêmico está muito aquém dessa evolução. As novas tecnologias são um achado para que as aulas e os conteúdos se tornem mais atrativos, o que não se vê são investimentos para que isso ocorra.

Muitos programas foram surgindo ao longo dos anos durante as últimas décadas, mas a sua efetividade, como dito, anteriormente, é questionável, basta se perguntar por onde andam os telecentros comunitários inaugurados aos montes pelo Brasil. Os Telecentros Comunitários foram espaços públicos criados para atender à população que não tem internet ou computador em casa, com acesso à internet banda larga, onde usuários podiam realizar diversas tarefas, estudos e pesquisas, ou pelo menos essa era sua função. Outros programas foram surgindo, mas nenhum deu o resultado desejado, por essa razão a tão falada inclusão digital no fim da década de 1990, início dos anos 2000, ainda é o desejo de grande parte da população. Fato é que a internet já está consideravelmente mais acessível, contudo não é ainda uma realidade universal. A camada menos favorecida da sociedade ainda luta pelo "pão, o arroz, o feijão e o aluguel” e isso não está nem perto de ser resolvido. Essas lacunas no acesso as novas tecnologias e a falta de inclusão digital, em um contexto como o atual, leva a questionar como estudantes terão uma educação de qualidade, se não estão mais em sala de aula em decorrência da pandemia do Coronavírus e precisam se orientar quanto às novas formas de estudo, o modelo EaD - Educação a Distância é uma nova e quiçá permanente forma de troca de conhecimentos entre educadores e educandos. A necessidade da população mais carente ultrapassa a tênue linha da fome. Eles necessitam de conhecimento que os possibilite acessar com dignidade os seus direitos mais básicos. É evidente a necessidade da população em relação à educação, ao acesso às novas tecnologias, e principalmente, às novas formas de ensino/aprendizagem adotadas a partir da pandemia.

Os municípios e os estados precisaram decretar o fechamento de pequenas e grandes empresas. Isso acarretou desemprego, subemprego e fome. O primeiro desfecho foi um assustador lockdown, em que ninguém sabia o que aconteceria. Os primeiros trabalhadores em home office, as primeiras contaminações e, por conseguinte as primeiras mortes. Na educação as primeiras tarefas, e os desafios começaram, pais desnorteados, filhos mais perdidos ainda, estava então inaugurada a nova forma de trocar conhecimentos, o modo EaD. Nesse momento da pandemia, em que todos estavam assustados com as notícias 
internacionais, as imagens de corredores lotados de pacientes, e a terrível necessidade de se fazer escolhas de quem recebe tratamento e quem não terá acesso, o brasileiro apesar de atônito, não teve a crença de que a doença era real. Tivemos nossos celulares carregados de fakenews que não mostravam a realidade da doença, mas uma roupagem de trama de conspiração política, de vírus criado em laboratório para vender-se a cura, que a população se sentiu num filme de ficção científica sem saída, a espera de um herói que viesse salvar a nação, mas talvez exatamente, por essa chuva de falsas afirmativas, o brasileiro não fez a quarentena como devia, e até hoje não adota os meios de segurança que foram sugeridos no início da pandemia. A segunda onda de contaminação chegou, surpreendeu a muitos, levou vários dos nossos parceiros, a vacina por sua vez, veio modesta, sob suspeitas de não funcionar e não imunizar, e aos poucos a população se rende a ela, na expectativa de que mais dia menos dia a vida volte ao normal, sem saber que talvez o normal já esteja disponível para download numa nova roupagem, o novo normal.

\section{Metodologia}

Este artigo adotou os pressupostos da pesquisa de revisão bibliográfica, acerca da inclusão e do letramento digital, que teve como base o levantamento criterioso de livros, artigos, dissertações, teses, relatórios oficiais. A análise dessa bibliografia variada garante a fundamentação teórica deste estudo e contribui para análise das informações coletadas.

Segundo alguns autores dispostos neste estudo, como: Behs (2020), Numico (2019) e Cesare (2020), o Brasil não estava pronto para o passo que a pandemia fez o país avançar. Para eles a falta de preparo, de infraestrutura, diferença social e distanciamento da população em relação às novas tecnologias dificultaram o trabalho de gestores escolares e professores. A pandemia provocou maior exclusão digital do que aproximou a população dela. Os reflexos que essa interação emergente terá no futuro da humanidade, como essa interação revolucionou o contato direto das diferentes gerações com as novas tec nologias e como isso impactará as próximas gerações é uma incógta. Pereira (2020), por sua vez, tem um olhar voltado para o meio em que vivemos. Como a parada pela pandemia aponta para os cuidados com o meio ambiente e como tudo pode ser diferente a partir das novas experiências humanas no contexto da Covid-19. Para ele é hora de incutir na cabeça do povo o quão importante é a educação sócio ambiental para a longevidade da vida humana sobre a terra, e como podemos esperar por novas primaveras.

Esse estudo traz uma discussão qualitativa de como as novas formas de saberes e os novos saberes interferem na dura realidade de milhões de famílias que poderiam estar inseridas no sistema educacional em sua nova formatação e devido às questões financeiras estão tão distantes de algo que parece certo, simples e comum a todos. Apesar de apontar alguns números que reforçam a nossa percepção quanto ao distanciamento entre o real e o ideal, a proposta é mostrar como a falta de acessibilidade pode interferir na qualidade do aprendizado que adquiriu um novo formato graças à Covid-19. Essa observação se baseou nos fatos cotidianos a partir de experiências compartilhadas onde o observador é também parte da pesquisa. Como professor e mestre, vivendo as mesmas dificuldades tal qual grande parte da população observada, foi preciso manter o foco no todo, evitando descrever uma situação particular, mas produzindo conhecimento de uma condição generalizada de falta de acesso às novas tecnologias que fomentam os novos saberes. Conforme Lüdke e André (1986) "para que se torne um instrumento válido e fidedigno de investigação científica, a observação precisa ser antes de tudo controlada e sistemática". Segundo os autores o sucesso da pesquisa está diretamente ligado ao planejamento e preparação do observador.

O conhecimento é um processo dinâmico e inacabado, serve como referencial para a pesquisa tanto qualitativa como quantitativa das relações sociais, como forma de busca de conhecimentos próprios das ciências exatas e experimentais. Portanto, o conhecimento e o saber são essenciais e existenciais no homem, ocorre entre todos os povos, independentemente de raça, crença, porquanto no homem o desejo de saber é inato. As diversificações na busca do saber e do conhecimento, segundo caracteres e potenciais humanos, originaram contingentes teóricos e 
práticos diferentes a serem destacados em níveis e espécies. O homem, em seu ato de conhecer, conhece a realidade vivencial, porque se os fenômenos agem sobre os seus sentidos, ele também pode agir sobre os fatos, adquirindo uma experiência pluridimensional do universo. De acordo com o movimento que orienta e organiza a atividade humana, conhecer, agir, aprender e outros conhecimentos, se dão em níveis diferenciados de apreensão da realidade, embora estejam inter-relacionados (Pereira et al. (2018) apud Tartuce, 2006, p.5)

Assim, esse trabalho tem como principal fonte de pesquisa o universo amplo, mais na parte confiável da internet. Tudo o que se pode descobrir está disponível atualmente na rede mundial de computadores. Assim para tratar da necessidade de acesso e acessibilidade, bem como as dificuldades enfrentadas pela população em um contexto totalmente hostil aos que não tem intimidade com a conectividade, muito menos com as novas tecnologias de informação e comunicação foi impossível fazer uma pesquisa tão vasta sem nos ater ao processo de divulgação de documentos, pesquisas e artigos pela internet. Todos os autores citados nesse trabalho, mesmo os que tiveram seus trabalhos publicados do modo tradicional, tem os seus textos disponibilizados em plataformas digitais, assim, alguns dos trabalhos foram publicados em revistas eletrônicas, outros no formato PDF, e trazem as informações necessárias para se discutir sobre o assunto que tem como foco as novas formas de ensinar e aprender no contexto de pandemia universal.

A Covid-19 apesar de ser um assunto novo, produziu mais material em um ano, do que assuntos como moda, emagrecimento ou estilo de vida. O "novo" Coronavírus tornou-se produto de consumo para estudantes em várias áreas do conhecimento, inclusive para quem deseja entender como isso se refletirá na educação daqui a cinco ou dez anos. Apesar de ser um assunto muito recente, a velocidade da notícia colocou a maioria das pessoas a par do que estava acontecendo no país e no mundo. Por essa razão, por tamanha velocidade e quantidade de trabalhos apresentados, nos foi possível achar um enorme arcabouço teórico e metodológico que nos pautasse para a realização dessa obra, que tem a intenção de abrir uma discussão sobre os inúmeros desafios, e as principais propostas para solução da falta de acesso e acessibilidade.

\section{Resultados e Discussão}

Indubitavelmente, as mudanças já chegaram, a evolução e a revolução já são uma realidade. É evidente que não temos carros que voam, tampouco viagem no tempo ou ainda o teletransporte, mas já contamos como uma tecnologia tão avançada que consegue colocar em contato pessoas em partes distintas e distantes umas das outras... Não. Não é o telefone, esse já ficou para trás, as novas tecnologias de Informação e comunicação aproximam e distanciam pessoas. Muitas vezes é possível ver várias pessoas reunidas, onde nenhuma delas está mantendo diálogo entre si, mas ao telefone conectadas com outros tantos que sequer podem estar perto. Tal avanço tecnológico tornou-se completamente útil, nesse momento de pandemia universal da Covid-19, em que o distanciamento social fez-se necessário, enfim é chegado “o tempo de afastar-se de abraçar” (Eclesiastes 1-5). Felizmente ou infelizmente, essas novas tecnologias surgiram antes da doença e muitas pessoas aprenderam a lidar com elas, entretanto, milhares de outros não tem acesso a essas ferramentas tão revolucionárias. Milhares de crianças, adolescentes e adultos ainda se sentem como analfabetos digitais. Enquanto toda essa revolução acontece, o homem se mostrava pouco preocupado com o presente, passando os dias com os olhos no futuro, não se lembrando do passado que forjou seu caráter, ignorando sinais de que uma mudança ultrarradical estava acontecendo, perdendo seu tempo sem viver o presente com a qualidade merecida, passando pouco tempo com os seus, trabalhando horas há mais para garantir um salário melhor, enquanto o corpo pedia socorro por um descanso, uma distração, um abraço. Agora, nem isso. Pereira (2020) trata dessa incompetência de se atentar ao presente, mas observa que no novo contexto o ser humano, enfim, pode se voltar para si e para o agora.

Defendo a premissa de que a humanidade estava voltada inteiramente para as projeções futuras com olhar muito efêmero sobre o presente e com poucas reminiscências do passado. A pandemia da Covid-19 coloca o ser humano, novamente, de frente com o presente, reivindicando um olhar para o que está acontecendo agora (Pereira, 2020). 
O isolamento social trouxe grandes tribulações para a vida das pessoas mais ativas, adolescentes acostumados a chafurdar-se nos seus quartos não perceberam que não poderiam sair de lá tão cedo. Enquanto isso, idosos, que deveriam estar quietos em casa, estavam nas ruas buscando a atividade que os fazia sentir-se vivos. Acabaram-se os bailes, esvaziaram-se as piscinas, fecharam-se os bares, levaram-se os livros, trancaram-se os portões das escolas. Viram-se idosos adoecerem, viu-se crescer o número de pessoas com o que seria o mal do século, a depressão, pais desesperados com os filhos em casa, falta de alimento nas mesas, deterioração da condição mental dos professores e uma desestrutura fenomenal no processo educacional. Abre-se, portanto, uma nova e importante porta na busca da qualificação educacional e profissional dentro dessa loucura chamada pandemia, ao EaD -Educação à Distância. Algo que já vinha sendo uma realidade nas universidades, proporcionando ao discente, maior liberdade em tratar de escolhas de locais e horários para se dedicar aos estudos. O Ensino à Distância inaugura uma nova forma de frequentar aulas, e isso se populariza no meio acadêmico. Com o novo contexto, as escolas primárias e secundárias se vêem envolvidas obrigatoriamente, no processo EaD, não que estivessem preparados para ela, como mesmo depois de mais de um ano de pandemia, continuam com inúmeras dificuldades, não tiveram tempo de aprender e precisaram enfrentar o novo, contando mais com a sorte do que com a capacitação e provisão de ferramentas. Nesse momento da história o ser humano precisa repensar suas necessidades, repensar os seus valores e consequentemente, revisar a própria vivência, revisitar os seus ensinamentos e tentar entender o seu novo contexto.

Portanto, somos convidados, cotidianamente, a ressignificar o presente, olhando com maior atenção o passado, avaliando nosso modo de ser e estar no mundo e, a partir disso, construirmos aprendizagens significativas que possam apontar horizontes possíveis para um futuro incerto. Talvez, a partir das aprendizagens fomentadas no seio dessa problemática, possamos vislumbrar uma primavera de esperanças (Pereira, 2020).

Quando se trata da nova forma de aprendizado provocado pelo colapso no sistema de vida humano vivenciado mundialmente, é preciso também entender como essa ferramenta inovadora de ensino chega até aos alunos. Em inúmeras escolas da rede pública, os alunos acompanham as aulas virtuais, mas não se adaptam totalmente a ela, os alunos precisam ter em suas mãos lápis, cadernos e muitos textos impressos. Algumas escolas deram início ao estudo EaD enviando as atividades para que os pais pudessem imprimir, contudo a realidade de vida das famílias é diferente e muitos que batalham todos os dias para ter o mínimo, passaram dificuldades para conseguir providenciar os trabalhos para os estudantes. Quantos mesmo tinham impressora em casa? Impressora? O que é isso? Bom, se não tem impressora, procura-se uma lanhouse, e assim os pais deveriam providenciar as cópias. "Dá quantas cópias, moço? Vai dar quanto? Nossa... e a mãe que é quem vai correr atrás da educação do filho, pensa: Vai faltar o do pão, mas meu filho precisa disso.

Um relatório conjunto da UNICEF - Fundo das Nações Unidas para a Infância e da ITU - União Internacional de Telecomunicações, apontaram segundo Numico, que "dois terços das crianças e adolescentes em idade escolar que vivem no planeta - 1,3 bilhão de meninas e meninos de 3 a 17 anos de idade - não têm conexão à internet em suas casas" (Numico, 2019). E o que dizer dessa mãe que luta todos os dias para garantir, “o pão, o arroz, o feijão e o aluguel”? E agora José? O fato é que a tão sonhada inclusão digital não aconteceu em tempo de salvar a educação, pelo menos não ainda. Muitas são as pesquisas para se encontrar uma solução, contudo, a falta de interesse político em um povo sábio, crítico, e independente impede que programas e projetos se tornem políticas públicas que evidenciem um desenvolvimento intelectual, com um discurso de falta de verba para financiamento, lembrando é claro, que no Brasil os investimentos em educação foram congelados por 20 anos. No entanto, o que Couto e Cruz, enfatizam é que mesmo em meio ao caos há desenvolvimento, crescimento e evolução. 
Entretanto, essas crises não podem ser analisadas apenas como negativas. Há crescimento, mudanças de costumes e práticas educativas salutares ao desenvolvimento das sociedades. Há avanços após o enfrentamento do caos. Pesquisas científicas descobrem novos tratamentos, remédios e vacinas para evitar e curar aquele mal. Os decretos, que impõem restrições à circulação das pessoas e as normas de higiene, podem ser educativos, com a revisão de costumes e práticas antigas a propagação de novos hábitos que contribuam para a saúde pública e a vivência em sociedade. E agora outro ciclo pandêmico, com a Covid-19, se abate sobre nós (Couto Cruz, 2020, p. 205).

O que o relatório, trazido por Numico (2019), evidencia é como a exclusão digital fomenta o distanciamento sócioeconômico-cultural, publicitando o quão medíocre está a qualidade educacional destinada à camada menos abastada da sociedade e como isso impede uma disputa leal por oportunidades. O Brasil é um país de extremos, onde uma pequena parte da população detém maior renda, enquanto grande parte dela vive com menos de um salário por mês. Em 2018 , $12,1 \%$ dos brasileiros viviam abaixo da linha de pobreza, em novembro de 2020 esse percentual alcançava os 24,7\%. Essa população sobrevive com menos de $\mathrm{R} \$ 500,00$ por mês, per capta. Dentro desse grupo, os considerados extremamente pobres - com renda mensal de até $\mathrm{R} \$ 151,00$ por pessoa do domicílio - eram 13,689 milhões em 2019, 6,5\% da população, de acordo com o IBGE (Instituto Brasileiro de Geografia e Estatística).

A exclusão digital, apontou o relatório, está perpetuando desigualdades que já dividem países e comunidades. Crianças e jovens de famílias mais pobres ficam cada vez mais para trás em relação aos seus pares com esse acesso e contam com poucas oportunidades de alcançá-los. Afinal, essa carência impede tais crianças e jovens de competirem na economia moderna e as isola do mundo (Numico, 2019).

O desejo desse artigo não é propriamente, abrir uma discussão político-partidária, não interessa que ocupa o lugar no poder, interessa como isso se reflete na qualidade de vida da sociedade. Os investimentos e fomento em educação, qualificação, profissionalização deveria independer exatamente disso. A lógica do capital é o oposto da lógica social, faria mais sentido se fossem diretamente proporcionais e não o contrário. O capital prega a exploração da mão de obra, o lucro acima de tudo, inclusive em detrimento a vida. O mundo já assistiu essa lógica em vários países, em vários momentos. Os mais recentes protagonizados pelo Brasil, especificamente, por Minas Gerais, estreitando um pouco mais, VALE lembrar o que aconteceu em Bento Rodrigues e Brumadinho.

O trabalhador aliena-se de seu trabalho porque é obrigado a vender sua atividade em troca de um salário que lhe assegure a sobrevivência. Isso quer dizer que para poder continuar a viver, o trabalhador deve vender uma parte de sua vida, que é a atividade por meio da qual ele poderia formar-se, fazendo da essência humana, isto é, das potências essenciais humanas formadas historicamente, a essência de sua individualidade (Brenner e Ferreira apud Saviani; Duarte, 2012, p. 27).

A forma de nos interagirmos precisa mudar, o povo dependente, precisa se libertar, adquirir conhecimento, condição de se impor e se opor ao que o capital nos oferece discurso utópico de quem ainda é otimista? Talvez, mas porque o povo brasileiro deveria deixar de acreditar num futuro melhor? É exatamente por acreditar nesse futuro, que agora, nesse presente, vendemos nossa mão de obra ao capital, numa tentativa de conseguir uma condição melhor em que se garanta não apenas, o pão, o arroz, o feijão e o aluguel, mas educação, conhecimento, capacitação, e porque não, lazer, moradia, saúde e segurança. Já se considera uma nova realidade, essa tal, internet, já se considera uma nova realidade essa tal Educação a Distância, já se considera como tal essa universalização das comunicações, e porque não se considera ainda a universalização do acesso as novas tecnologias de informação e comunicação?

Esse fenômeno já integra desde as dimensões do mundo da vida, onde está o nosso arranjo existencial, cultural, nossas relações primeiras e afetivas, até o mundo do sistema, orientado por outra racionalidade sobre a forma em que se organizam os espaços e tempos, na lógica do sistema capitalista (Pereira, 2020). 
Muitas perguntas, poucas respostas, mas o que move o mundo não são simplesmente as respostas. Tudo agora se faz em plataformas digitais, os alunos têm o AVA - Ambiente Virtual do Aluno, tele aulas, mas isso o brasileiro já conhece, quem não se lembra dos telecursos, ideia revolucionária nas décadas de 1970 e 1980. Caíram em desuso, mas para dar lugar a outras inovações, youtube, agora, tem tutorial para tudo, inclusive para fabricar bombas, arrombar portas, roubar casas, fazer deliciosos quitutes, vender dinheiro falso. Quanta informação!

As nossas relações mudaram. Os relacionamentos já não são mais no mundo real, mas no virtual, já não se olha nos olhos para se dizer "te amo", existe uma tela de touchscreen entre os casais. As pessoas não se conhecem mais no cinema, no shopping ou na pracinha do centro da cidade, naquele carrinho de cachorro quente, mequetrefe, mas nos aplicativos de namoro. Desculpe, nos apps de relacionamento.

As trocas de conteúdos eróticos nas redes mostram que o sexo não precisa mais dos corpos. É um brilho efêmero nas carícias de nossas telas. As performances sexuais circulam rapidamente para o consumo veloz e arrebatador. No nosso isolamento social, o cibersexo são artifícios e textualidades compostos por sons, imagens fotográficas e videográficas, signos diversos que se misturam, se confundem e são remixados na produção de novos produtos para diferentes sentidos (Couto; Couto; Cruz, 2020, p.208).

A relação homem e máquina, homem e tecnologia, tem que ultrapassar essa comorbidade emocional que assola o mundo. É preciso ver além do touch, vivenciar as inovações tecnológicas para além do universo individualista que a humanidade adotou bem antes da pandemia quando se isolou em seus pequenos mundos. Estar em casa causa inúmeros transtornos e maior consumo dentro dos lares. Muitas crianças tinham na escola pelo menos uma refeição diária, e às vezes, era a única refeição completa do dia. Contudo estar presas em casa provoca maior gastos, motivando inclusive a busca por benefícios eventuais, como o de alimentação, por exemplo. As facilidades do acesso digital revolucionaram a maneira do ser humano interagir, e sua utilização sofreu grande aumento durante a pandemia, há mais de um ano os serviços interativos passaram a fazer parte do nosso cotidiano.

Se a maneira como interagimos em nível pessoal foi transformada, também foi revolucionada a maneira como interagimos com o estado e nos beneficiamos dos serviços. O "e-qualquer coisa" (como e-commerce, e-health, eservice, e-work) abriu novas possibilidades, mas ao mesmo tempo criou espaços para novas exclusões em relação àqueles que não estão "nas condições", não podem se permitir , não estão aptos" a usar as tecnologias digitais. (Numico, 2019).

Tudo está sendo disponibilizado via internet, para os que detém o conhecimento, transações monetárias, transferências bancárias, cadastros em empresas multinacionais, é uma praticidade. Porém, a falta de acesso e de acessibilidade provoca um distanciamento gradual e nocivo que reflete na exclusão em massa de inúmeras famílias, que necessitam de ajuda para garantirem seu acesso aos serviços ofertados em plataformas digitais. Analisem um pouco acerca do acesso a plataformas de equipamentos que deveriam garantir direitos, como o portal Meu INSS, Meu GOV, Cadastro Único, Bolsa Família. Quem acessa ou deveria acessar essas plataformas, são exatamente, as pessoas de menor renda, de menor conhecimento, de menor autonomia, e que são impreterivelmente, as pessoas que mais necessitam acessar tais benefícios. Essa dicotomia aponta para o maior distanciamento social, para além da pandemia, um distanciamento pré-existente que só faz aumentar, deixando claro que o distanciamento social é provocado pela diferença salarial e classe social. Parece haver algo de muito errado nessa lógica.

Justamente aqueles que mais precisam faltam à chamada da conexão digital e "as divisões sociais se replicam online". E como "os serviços essenciais estão cada vez mais on-line, a inclusão digital se torna indispensável para a participação social mais essencial", a tal ponto que "deve ser considerado um direito humano" (Numico, 2019). 
A camada menos favorecida, precisa mais, tem menos, e parece estar cada vez mais distante dessa nova realidade. Os direitos sociais parecem escapar por entre os dedos. Escorrem como a água que contorna seus obstáculos e esvai-se. Por onde anda o artigo $5^{\circ}$ da Constituição Federal? Aliás não somente o artigo $5^{\circ}$ "Todas as pessoas são iguais perante a Lei”, mas também o artigo 205 da mesma constituição que diz que “A educação, direito de todos e dever do Estado e da família, será promovida e incentivada com a colaboração da sociedade, visando ao pleno desenvolvimento da pessoa, seu preparo para o exercício da cidadania e sua qualificação para o trabalho". Quantas violações mais o povo brasileiro deverá se submeter para viver condições sub-humanas e degradantes? Vimos todos os dias o legislativo criar leis e mais leis só para garantir que LEI seja obedecida.

Já foi dito anteriormente, não são as respostas que movem o mundo, mas faz-se necessário tentar responder algumas delas. Uma das opções em estudo na atualidade seria a concessão de um chip com internet para que alunos não ficassem sem acesso e tivessem possibilidade de estudar os conteúdos sem quaisquer prejuízos. É claro que este chip deve vir com vários bloqueios, para evitar o gasto da internet com acessos como Kwai, TicToc, filmes, para ser utilizado apenas para fins acadêmicos. A mesma proposta poderá ser adotada para a Conferência Nacional da Assistência Social, afinal os delegados não são apenas doutores, mas tem uma grande participação da sociedade civil. Mas a internet não é a única barreira, o equipamento e o desconhecimento do funcionamento deles também pode ser um item excludente. Mas melhor não se ater aos problemas, esta pode ser uma solução simples para um problema gigantesco. De acordo com Patrícia Lobaccaro (2020), em artigo disponibilizado no portal UOL, a CUFA - Central Única das Favelas, lançou a campanha "Alô Social". Esta campanha disponibilizou 500 mil chips de celular com internet em cerca de 5 mil favelas brasileiras, considerado pela jornalista como “o maior projeto de conectividade feito nesses territórios". A campanha tem como objetivo a democratização do acesso à comunicação e internet, com previsão de impacto de mais de 4 milhões de pessoas até junho de 2021.

Recentemente, o Governo Federal vetou o projeto de Lei PL 3.853/2020, que previa a doação de tablets para os alunos tanto da rede pública como da rede privada, além de ofertar material didático e pacote de dados a estudantes desde a educação básica até o ensino superior, permitindo que eles tivessem acesso as atividades curriculares durante o período em que as escolas permanecem fechadas devido à pandemia. De acordo com o Projeto de Lei estaria destinado a alunos que estejam cadastrados no CAD Único - Cadastro Único do Governo Federal, além de comunidades indígenas e quilombolas. Segundo a Agência Senado, o propositor da Lei, o Deputado Danilo Cabral pediu a derrubada do veto do presidente da república, na sessão do dia 15 de abril. Segundo ele o Ministério da Educação foi "ausente" e a educação a mais afetada pelo problema gerado pela pandemia do Coronavírus.

"Além dos cortes orçamentários, todos nós sabemos que a educação foi uma das áreas mais afetadas pela pandemia, especialmente as redes públicas de ensino básico. O Ministério da Educação foi ausente ao longo do ano passado e continua assim, restando aos estados e municípios adotarem medidas isoladamente. Temos visto o aumento da desigualdade e corremos o risco de um 'apagão' educacional no país, precisamos agir" (Danilo Cabral, líder do PSB).

Na verdade, o que resolveria o problema da exclusão digital, bem como a exclusão social, seria uma política pública voltada para a educação de qualidade, com investimentos econômicos que propiciem criação de emprego e renda, e políticas públicas de proteção social básica, impedindo que o sistema tenha que lidar com necessidades que exijam os serviços de proteção especial. Tratar o problema em sua raiz, garantindo aqueles direitos mais básicos, como direito à vida, por exemplo, buscando evitar propostas excludentes, e reformas administrativas nos três níveis e nos três campos do poder. É nessa hora que deve ser lembrada o que reza a configuração política no Brasil, no que tange à democracia: nosso direito de ser obrigado a votar a cada eleição. 
Tanto alunos quanto professores experimentaram mudanças de comportamento dentro da nova forma de ensinar e aprender. Os professores que já se dedicavam a tarefas fora da sala de aula, como correção de provas e preparo do plano de aula, se viram mais preocupados com os estudantes e mudaram sua rotina de trabalho no formado do ensino remoto, assim o número de horas trabalhadas e não remuneradas aumentou, e as ferramentas se multiplicaram. Em considerando as formas de trabalho remonto no contexto de pandemia, o campeão foi o WhatsApp e o email. Muito mais dinâmico, os professores não só ofereciam aulas remotas como participavam também de reuniões e cursos online. A Fundação Carlos Chagas realizou uma pesquisa (ver Figura 1) em que mostra como as ferramentas influenciaram no trabalho remoto.

Figura 1: Ferramentas influenciaram no trabalho remoto.

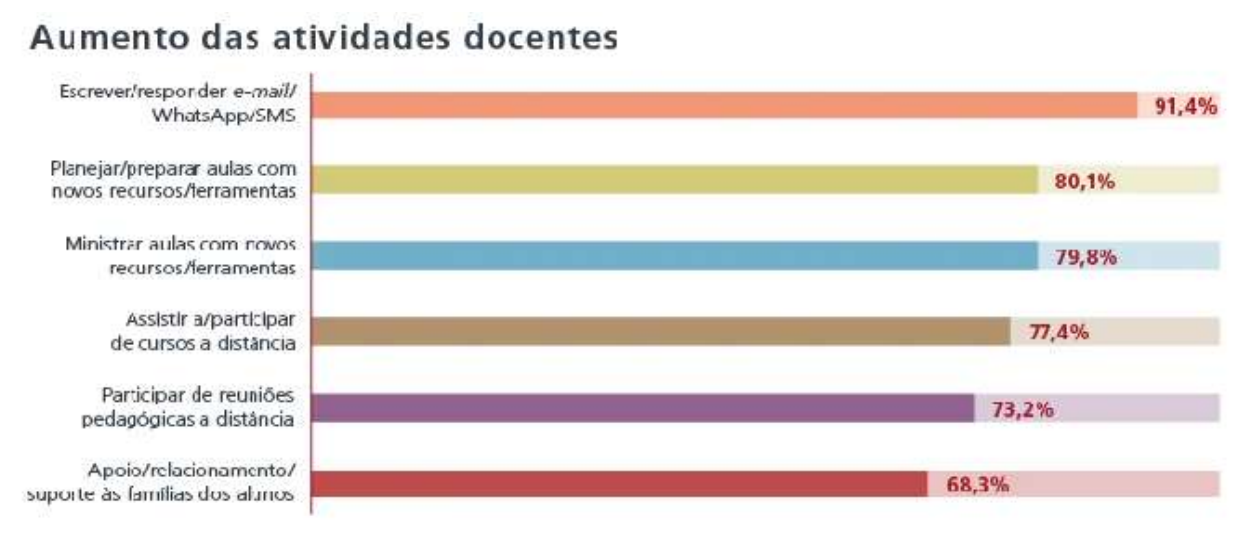

Fonte: Fundação Carlos Chagas (2020).

Infelizmente, o despreparo emocional também foi um fator que prejudicou a adaptação a nova forma de trocar experiências entre alunos e professores. Muitos pais tiveram acesso ao telefone dos professores, e a imaturidade dessa nova relação provocou abusos, assédios e problemas sérios para ambos os lados. Mesmo impedidos de interagir nos grupos em que os professores enviavam as aulas, muitos pais não se detiveram e entraram em contato nos ambientes privados de inúmeros professores. Esses foram relatos de alguns conhecidos que precisaram fazer, inclusive, boletins de ocorrência, para se protegerem de possíveis ameaças.

Em contrapartida o desenvolvimento educacional do aluno ficou comprometido. A mesma pesquisa da Fundação Carlos Chagas, aponta que os alunos que já têm bom rendimento escolar seriam mais bem-sucedidos no estudo online. A pesquisa ouviu os professores sobre a qualidade mental desses alunos reclusos participantes do EaD. De acordo com os professores aumentou o número de alunos com depressão enquanto diminuiu o aprendizado (ver Figura 2). Esse comprometimento na aprendizagem só mostrará suas consequências nos próximos anos. No entanto o momento é preocupante. 
Figura 2: Efeito da suspensão das aulas presenciais.

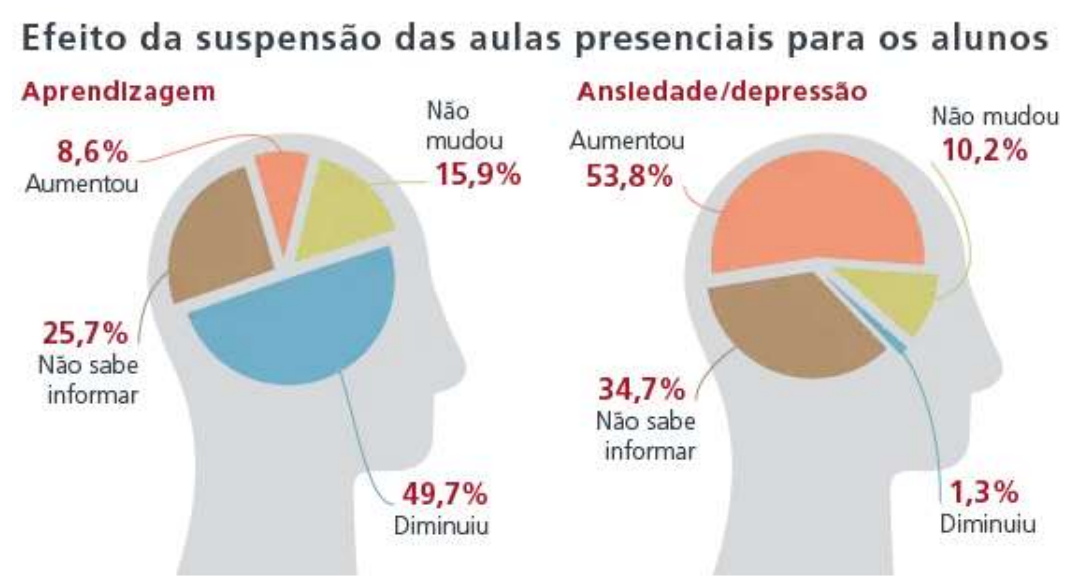

Fonte: Fundação Carlos Chagas (2020).

Esse comprometimento na educação foi refletido no âmbito do acesso ao auxílio emergencial criado pelo Governo Federal. Com a criação do auxílio milhares de trabalhadores precisaram correr para as filas do único banco autorizado a fazer os pagamentos. No Brasil os serviços assistenciais viram o número de necessitados praticamente dobrar. Acessar o auxílio emergencial tornou-se um desafio para a maioria dos beneficiários. Primeiro a burocracia que é um legado no nosso país sempre foi um entrave, o sistema sobrecarregado, não funcionava perfeitamente, as informações chegavam aos montes a todo momento, um desserviço no que diz respeito a comunicação, inúmeras pessoas não conseguiam fazer as solicitações. Os telefones dos serviços de Cadastro Único e CRAS - Centro de Referência da Assistência Social, não paravam, apesar de o sistema nada ter haver com a Assistência Social. Diante do quadro calamitoso o único lugar que teria todas as respostas seria a instituição pagadora que se viu pressionada. Num momento em que a ordem era ficar em casa, as filas faziam curvas nas esquinas, enquanto a população se acumulava para tentar resolver a questão. Couto; Couto e Cruz (2020) lembram "Sem contas bancárias, semiletrados e muitas dificuldades para lidar com os sistemas eletrônicos, [...] e pessoas aglomeradas, se expondo ao vírus, se espalharam por toda parte”. Isso tudo mostrou apenas o quanto a população está despreparada para o novo universo tecnológico que permeia as instituições de educação, bancos e empresas de um modo geral.

A economia do país ainda não entrou em colapso, mas pode entrar a qualquer momento. Para pequenos empresários os efeitos da pandemia já se mostraram mais arrasadores do que para os grandes. Muitas portas se fecharam e o desemprego aumentou consideravelmente. De 2019 a 2020 o desempregou aumento em 1,9\%, enquanto subiu 1\% apenas nos primeiros meses de 2021. Da mesma forma o número de pessoas passando fome só aumentou. Em contrapartida os de usuários da internet se mantiveram sem alteração até a presente data, conforme o quadro abaixo.

Quadro 1: Quadro comparativo da situação do brasileiro durante a pandemia.

\begin{tabular}{|l|c|c|c|}
\hline & $\mathbf{2 0 1 9}$ & $\mathbf{2 0 2 0}$ & Primeiros meses de 2021 \\
\hline Desemprego & $11,9 \%$ & $13,5 \%$ & $14,5 \%$ \\
\hline Fome & 10,3 milhões & 19 milhões & 19,1 milhões \\
\hline Usuários da internet & $.126,9$ milhões & 134 milhões & 134 milhões \\
\hline
\end{tabular}

Fonte: Inquérito Nacional sobre Insegurança Alimentar no Contexto da Pandemia da Covid-19. 
O estudo apontou que são muitas as necessidades de adequação à nova realidade brasileira. Os países mais ricos e desenvolvidos se prepararam para essa realidade, já os países de terceiro mundo, bem como os países em processo de desenvolvimento estão muito distantes de solucionar seus problemas. O Brasil em particular, tem um histórico de corrupção e superfaturamento inclusive dos gêneros mais básicos na pandemia, ou em qualquer outra situação de emergência ou calamidade. Infelizmente, essa forma de se aproveitar da situação é uma característica forte no brasileiro, independente da sua posição social e/ou política.

Contudo, inúmeros desafios estão se apresentando a sociedade brasileira para que os reflexos dessa pandemia póscovid-19 sejam menos agressivos à população. Assim, há que se pensar em soluções práticas, que não impedirão o desenvolvimento do país, e ainda oferecerão como saída para a crise, soluções viáveis, mesmo que a médio ou longo prazo, porque no mais curto prazo, as ações serão apenas para aplacar a dor de muitos.

Quadro 2: Desafios da educação a distância no contexto pós-covid-19.

\begin{tabular}{|c|c|}
\hline DESAFIOS & PROPOSTAS \\
\hline 1. Investimento em Políticas Públicas na Educação básica & $\begin{array}{l}\text { Descongelamento dos investimentos, e aumento do } \\
\text { percentual destinado à educação }\end{array}$ \\
\hline 2. Investimento em infraestrutura & $\begin{array}{l}\text { Investir em melhor qualidade da internet, diminuir os custos } \\
\text { dos equipamentos por meio de incentivos fiscais }\end{array}$ \\
\hline 3. Formação de Professores & $\begin{array}{l}\text { Desenvolvimento de novas metodologias, capacitação } \\
\text { contínua }\end{array}$ \\
\hline 4. Valorização de Professores & $\begin{array}{l}\text { Melhorias salariais, planos de cargos e carreiras, } \\
\text { pagamentos em dia }\end{array}$ \\
\hline 5. Repensar o Ensino Remoto & Adequando as escolas e a metodologia utilizada \\
\hline 5. Revisão do Projeto Pedagógico das Escolas & Incluir novos conteúdos mais aproximados a nova realidade \\
\hline $\begin{array}{l}\text { 6. Investimentos em Projetos de Educação Socioambiental } \\
\text { com a defesa da vida }\end{array}$ & $\begin{array}{l}\text { Revisão da Grade curricular para inserção de novas pautas } \\
\text { que interajam diretamente com as condições de vida no } \\
\text { planeta }\end{array}$ \\
\hline 7. Redefinição de espaços e tempos de aprendizagem & $\begin{array}{l}\text { Ampliação das estruturas físicas, com maior número de } \\
\text { salas de aula, reduzindo a quantidade de aluno por metro } \\
\text { quadrado com laboratórios de informática bem estruturados }\end{array}$ \\
\hline 8. Olhar para os estudantes da Escola Básica Pública & Destinar mais recursos à educação \\
\hline 9. Reforma tributária & Reduzir os impostos relacionados a eletroeletrônicos \\
\hline 10. Atentar-se a Lei Máxima do país & $\begin{array}{l}\text { Respeitar a Constituição Federal de } 1988 \text { sem ter que fazer } \\
\text { leis para obedecer a LEI. }\end{array}$ \\
\hline
\end{tabular}

Fonte: Autores.

\section{Considerações Finais}

O mundo como conhecíamos, não existe mais. É hora de nos adaptarmos à nova realidade que o século XXI trouxe no limiar da sua segunda década. Não mais se virá o mundo sem a Covid, assim como não há mais o mundo sem dengue ou H1N1. Tudo se transforma e o ser humano se vê na qualidade de transformado e transformador. Em se tratando de consequências, o homem a julgar por suas atitudes, muitas vezes impensadas, é o grande protagonista dessa história. Mudanças que vem para o bem ou para o mal, mas vem das mãos daquele que atua sobre a terra.

Há quem diga que tudo isso seja a vontade de Deus, há quem diga que isso é a ação do Diabo, mas quem somos nós para lavarmos as nossas mãos como fez Pilatos e jogarmos toda a culpa neles. O Diabo só desamarrou o burro, e mesmo com toda a sua piedade e benevolência, e poder de perdoar e de nos livrar de todo o mal, Deus não desmente a sua própria palavra, 
que diz "porque tudo o que o homem semear, isso também ceifará", (Gálatas 6-7). Então é hora de revisitar o passado, ressignificar o presente e construir um futuro diferente para que a humanidade passe por toda essa tempestade e saia mais forte, revigorada e menos presunçosa.

A atual conjuntura nos força a reconsiderar nossos planos, nossos projetos, e olhar a questão educacional por outros prismas para além da formação acadêmica, mas para a formação cidadã, respeitando as diferenças que sempre existirão, no entanto, não permitindo que essa diferença seja excludente. Não há um sequer que consiga viver só. O homem é um ser social, já dizia Aristóteles, interdependentes, precisam uns dos outros para sobreviver, contudo, a realidade se mostra conflitante. Somos todos seres sociais, interdependentes, porém não preciso do outro, posso me virar sozinho. O pensamento humano é meio controverso mesmo.

Em um sistema em permanente mudança, não se pode aceitar que o homem viva a Síndrome de Gabriela. Certamente já se ouviu em algum momento a música de Dorival Caymmi: "Eu nasci assim, eu vivi assim, vou ser sempre assim, Gabriela". Não "eu prefiro ser aquela metamorfose ambulante", como dizia Raul. O homem não consegue passar por um período tão longo sem mudanças, porque as constantes mudanças fazem parte do desenvolvimento humano, tanto físico, social e cultural em qualquer tempo e lugar.

É claro que os costumes, o folclore, as manias e a cultura permanecem, mas até elas se adéquam com o tempo. Quem diria, por exemplo, que o Congado um dia fosse fazer parte de uma missa católica, mas pasmem, um padre inseriu na sua missa a manifestação africana. É obvio que muitos fiéis queriam apedrejá-lo, mas o sacerdote não se deteve, e o povo compreendeu que essa cultura faz parte da cultura brasileira, porque então, ser excludente enquanto ele pregava o amor ao próximo?

É impensável o mundo desconectado, então é melhor se adaptar, porque o distanciamento só está começando, a alienação é só um sinal de que muitos vão passar forme e sede, físico e mental. Enquanto os governantes não pensarem no coletivo, mas apenas nos interesses próprios, o que chamamos de minoria, que na realidade é a maioria, vai ficar para trás no trem da história. E a minoria, os detentores da riqueza vão estar sempre a frente na disputa do mercado, na disputa do trabalho, na disputa do conforto, na disputa do conhecimento e quiçá um dia, nem haja mais disputa, porque a maioria esqueceu de como é ter esperança.

O trabalho só está começando, porque o rumo da educação no pós-pandemia será definido nos próximos meses, enquanto persistirem os sintomas da doença, bem como os sintomas da falta de acesso e acessibilidade, com resultados lamentáveis na educação. Fato é que os conteúdos estão sendo despejados sobre os alunos e resolvidos de qualquer jeito, entregues nas escolas ainda no formato lápis, papel e caneta e não nas plataformas digitais. As coisas não têm funcionado como deveriam e tem deixado muito a desejar. Dessa forma os alunos não estão se empenhando como deveriam, nem mesmo podendo acessar seus trabalhos através da internet.

Isso se refletirá com mais veemência no futuro, uma vez que todo o avanço nas comunicações virtuais era esperado para daqui dez anos. A pandemia fez somente acontecer um acelerar dessa evolução que pegou todos despreparados e pulou etapas, como num casamento às pressas em que o casal não tem tempo para fazer o reconhecimento do outro. Etapas importantes durante a evolução que não se respeitou e que por fim trará de certo sérias consequências. Di Cesari (2020), coloca muito bem a sua preocupação quanto ao futuro da economia, quando pontua, o caos econômico e a recessão que o planeta viverá no pós-pandemia. Lembra ainda em seu estudo que quem não estiver preparado vai ficar para trás.

Ao final dessa equação, teremos um mundo em que os negócios se voltarão não apenas à criação de valor para o cliente, garantindo uma boa experiência, mas também uma convivência virtual, com o sentimento de engajamento e pertencimento que reúne o cliente, o colaborador e o parceiro, todos num ambiente de compartilhamento e unicidade. Depois da pandemia, surge um mundo digital, acelerado para um cenário que naturalmente ocorreria daqui, aproximadamente, dez anos. Quem se preparar para isso, seguirá o curso natural dos negócios (Di Cesare, 2020). 
O futuro é incerto. Como se o mundo estivesse passando mais uma vez por uma grande guerra. O incrível é que a guerra que travamos é contra o invisível, mas infelizmente, notável vírus, que ceifa, ou deixa sequelas. Tudo poderá no futuro fazer algum sentido. De acordo com Piccolotto (2020), ainda não se pode afirmar nada sobre o futuro das relações após o retorno da normalidade, mesmo porque provavelmente, não teremos um velho normal, mas o novo normal. Aprendemos a nos isolar, a nos comunicar, a trabalhar de forma diferente, talvez no novo normal não saibamos, nunca mais, a abraçar novamente, mas isso somente o futuro vai dizer. O que há de certo é que a humanidade enfim, tem um desafio em comum. Nunca na história da humanidade viu-se um desafio coletivo como o desafio tecnológico. Algo que abrangesse não um país inteiro, ou um continente, mas o planeta se viu nesse drama.

Um elemento, no entanto, deve ser considerado no rol de transformações que temos vivido. Pela primeira vez, a humanidade enfrenta um desafio coletivo em meio à uma revolução tecnológica. E graças às novas soluções digitais foi possível manter relativa normalidade em muitos aspectos do cotidiano: diversas organizações continuaram ativas graças ao trabalho remoto, pessoas puderam manter interações sociais por meio de seus smartphones e aplicativos de mensagens e de vídeos, e também o poder público pode explorar novas formas de atuação e oferta de serviços à população em um contexto de isolamento social (Piccolotto, 2020).

A Organização das Nações Unidas considera que esse momento histórico é um dos mais desafiadores de todos os tempos perdendo apenas para a Segunda Guerra Mundial. Nenhum outro desafio foi tão amplo, resvalando em todos os países do mundo como esses dois que envolveram toda a humanidade. Mesmo com toda a diferença entre as nações, como poder econômico, tecnológico ou bélico, todos sem exceção experimentaram da corrida pela vida, pela prevenção, pela busca da vacina, do afastamento, do fechamento de comércio, "prisões domiciliares" aos montes e o deflagrar de uma guerra contra um mal desconhecido.

Fato é que o trabalho remoto deu certo para muitos, o estudo EaD foi um achado para grande parte da população, contudo, nem todos estão dando conta de seguir em frente diante do exposto pela pandemia, e a dúvida é, quem vai conseguir fazer a diferença e se firmar no mercado, enfrentando os desafios e conquistando seu lugar ao sol. Nesse momento o que pode ser feito é pesquisar, estudar, tentar conhecer soluções e se possível adquirir bons equipamentos e internet banda larga, porque o futuro é digital.

Esse futuro trará um leque de opções para novas investigações, novas proposições que poderão enriquecer ainda mais a biblioteca digital disposta na rede mundial de computadores. Esse futuro digital fomentará a discussão pelo direito, pela acessibilidade, pelo poder gerado a partir do conhecimento e principalmente sobre as responsabilidades que serão impostas no período pós-Covid. O vasto material disponível nas inúmeras plataformas digitais pode ser acrescido de outros tantos, dada a variedade de assuntos existente no novo contexto pandêmico vivido pela humanidade. Dessa forma enxergando que há muito mais para saber acerca dos desafios e das conseqüências geradas graças a esse momento, e as dúvidas que pairam sobre como será o amanhã, sugere-se uma discussão sobre a relação entre o grau de conhecimento e o nível de dependência da pessoa humana no que diz respeito as tomadas de decisão, como o maior arcabouço teórico pode fomentar a participação cidadã nas discussões de assuntos inerentes ao desenvolvimento humano para melhor qualidade de vida, e a discussão ainda de como os alunos dessa geração poderão fazer diferença no futuro. Mesmo sendo de forma híbrida (presencial e virtual) o retorno as aulas, há que se discutir políticas públicas que prevejam a capacitação e aparelhamentos dos professores e unidades escolares do sistema público educacional. Se o futuro é digital, os alunos de hoje são os precursores de uma nova geração de docentes totalmente conectados e preparados para o enfrentamento das mazelas oriundas do início da segunda década dos anos 2000.

\section{Referências}

Arruda, E. P. (2020). Educação remota emergencial: elementos para políticas públicas na educação brasileira em tempos de Covid-19. Em Rede-Revista de Educação a Distância, 7 (1), 257-275. 
Behs E. (2020). Exclusão digital impede pleno desenvolvimento de crianças e jovens. http://www.ihu.unisinos.br/606256-exclusao-digital-impede-plenodesenvolvimento-de-criancas-e-jovens.

Brasil. Constituição da República Federativa do Brasil de 1988. Diário Oficial da União.

Brenner, C. E. B., \& Ferreira, L. S. (2020). Gestão Escolar e conflitos: impactos no trabalho pedagógico dos professores. Educação, 8 (3), 11-26.

Cesare F. D. (2020). A pandemia que empurrou a sociedade para o digital: como será depois? https://inforchannel.com.br/a-pandemia-que-empurrou-asociedade-para-o-digital-como-sera-depois.

Couto, E. S., Couto, E. S., \& Cruz, I. de M. P. (2020). \#fiqueemcasa: Educação na pandemia da covid-19. Educação, 8 (3), $200-217$.

Cury, C. R. J. (2012). Direito à educação: direito à igualdade, direito à diferença. https://www.scielo.br/j/cp/a/x6g8nsWJ4MSk6K58885J3jd/?lang=pt

Dorow, E. (2020). A transformação digital no mundo pós-pandemia. https://www.senior.com.br/blog/a-transformacao-digital-no-mundo-pos-pandemia.

Fundação Carlos Chagas (2020). Educação escolar em tempos de pandemia. https://www.fcc.org.br/fcc/educacao-pesquisa/educacao-escolar-em-tempos-depandemia-informe-n-1.

Fundação Carlos Chagas (2020). Educação escolar em tempos de pandemia na visão de professoras/es da educação básica. FCC.

Inquérito Nacional sobre Insegurança Alimentar no Contexto da Pandemia da Covid-19 (2021). http://pesquisassan.net.br/olheparaafome.

Instituto Península (2020). Em quarentena: $83 \%$ dos professores ainda se sentem despreparados para ensino virtual. https://institutopeninsula.org.br/emquarentena-83-dos-professores-ainda-se-sentem-despreparados-para-ensino-virtual-2.

Lobaccaro, P. (2020). O que a pandemia nos mostrou sobre a educação no Brasil. https://www.uol.com.br/ecoa/colunas/patricia-lobaccaro/2020/11/24/o-quea-pandemia-nos-mostrou-sobre-a-educacao-no-brasil.htm.

Ludke, M.; Andre, M. E. D. A. (2013). Pesquisas em educação: uma abordagem qualitativa. E. P. U. 5.5).

Ministério Público do Paraná, Nota técnica: Ensino a distância na educação básica frente à pandemia da covid-19 (2020). https://crianca.mppr.mp.br/arquivos/File/publi/todos_pela_educacao/nota_tecnica_ensino_a_distancia_todospelaeducacao_covid19.pdf.

Montini, A. (2020). O que era uma opção virou necessidade: a transformação digital em tempos de pandemia! https://noomis.febraban.org.br/especialista/alessandra-montini/o-que-era-uma-opcao-virou-necessidade-a-transformacao-digital-em-tempos-de-pandemia.

Munastiwi, E., \& Puryono, S. (2021). Unprepared Management Decreases Education Performance in Kindergartens during Covid-19 Pandemic. Heliyon, e07138.

Newman, D. (2020). As 10 maiores transformações digitais de 2020: conclusões do pós-pandemia. https://forbes.com.br/forbes-tech/2020/08/as-10-maiorestransformacoes-digitais-de-2020-conclusoes-do-pos-pandemia.

Numico, S. (2019). 'Inclusão digital’ como direito humano. http://www.ihu.unisinos.br/78-noticias/592669-inclusao-digital-como-direito-humano.

ONU. Declaração dos direitos humanos (1948). https://www.unicef.org/brazil/declaracao-universal-dos-direitos-humanos.

Pereira, V. A. (2020). Como está sendo o agora: aprendizagens na travessia da pandemia da covid-19. Editora Amplla.

Pereira, A. S., Shitsuka, D. M., Parreira, F. J., \& Shitsuka, R. (2018). Metodologia da pesquisa científica. (pp. 3-9).

Piccolotto, L. (2020). Mundo pós-pandemia vai ser mais digital e, ao mesmo tempo, mais humano. https://www.jota.info/coberturas-especiais/inova-eacao/mundo-pos-pandemia-vai-ser-mais-digital-e-ao-mesmo-tempo-mais-humano-09062020.

Portal SAE Digital. Educação e Coronavírus - Quais são os impactos da pandemia? https://sae.digital/educacao-e-coronavirus.

Putra, P., Liriwati, F. Y., Tahrim, T., Syafrudin, S., \& Aslan, A. (2020). The students learning from home experiences during Covid-19 school closures policy in Indonesia. Jurnal Iqra': Kajian Ilmu Pendidikan, 5 (2), 30-42.

Sato, M. (2020). Os condenados da pandemia. https://editorasustentavel.com.br/os-condenados-da-pandemia.

Silva, F. T. (2020). Currículo de transição: uma saída para a educação pós pandemia. https://www.futura.org.br/educacao-brasileira-na-pandemia-em-2020-eos-desafios-de-2021.

Telecentro: Espaço de inclusão digital. http://www.telecentro.buri.org.br/apostilas/doc_009.pdf.

Turchi, S. (2020). A era digital revolucionou a maneira como gerações encaram a tecnologia. http://sandraturchi.com.br/era-geracoes-tecnologia. 